\title{
Guidelines for mineral fibre analyses in biological samples: report of the ERS Working Group
}

\author{
P. De Vuyst*, A. Karjalainen+, P. Dumortier*, J-C. Pairon‡, E. Monsó\#, P. Brochard\$, \\ H. Teschler**, A. Tossavainen+, A. Gibbs $\$$
}

Guidelines for mineral fibre analyses in biological samples. Report of the ERS Working Group. P. De Vuyst, A. Karjalainen, P. Dumortier, J-C. Pairon, E. Monsó, P. Brochard, H. Teschler, A. Tossavainen, A. Gibbs. CERS Journals Ltd 1998.

ABSTRACT: Microscopic techniques for analysing asbestos fibres in lung tissue and bronchoalveolar lavage have provided major information in the understanding of asbestos-related diseases. These analyses are increasingly applied for clinical work and medicolegal problems. Differences in sampling, preparation and counting techniques, definitions of reference populations and expression of results have caused major difficulties in comparing results from different laboratories. Therefore it appeared necessary to set a goal to harmonize these analyses between the European laboratories active in this field.

This article summarizes the work of a European Respiratory Society working group with participation from nine European laboratories. The five main issues touched upon are: 1) definitions of control populations and reference levels; 2) sampling, preparation and analytical techniques; 3) asbestos fibres in lung tissues in different pathologies; 4) asbestos bodies in lung tissue, bronchoalveolar lavage and sputum; and 5) basis for the interpretation of fibres and asbestos bodies in biological samples.

These guidelines indicate the crucial importance of several factors for the interpretation of the results; namely, adequate sampling, comparable analytical procedures and expression of the results, the use of well-defined reference populations, and a comprehensive understanding of the factors affecting the fibre retention and the dose-responses associated with the different asbestos-related diseases.

Eur Respir J 1998; 11: 1416-1426.
*Hôpital Erasme, Brussels, Belgium. +Finnish Institute of Occupational Health, Helsinki, Finland. INSERM and Laboratoire d'Étude des Particules Inhalées, Paris, France. \#Hospital Germans Trias I Pujol, Badalona, Spain. \&Laboratoire d'Étude des Particules Inhalées, Paris and Université de Bordeaux, France. **Ruhrlandklinik, Essen, Germany. sLlandough Hospital, Penarth, South Glamorgan, UK.

Correspondence: P. De Vuyst, Hôpital Erasme, Chest Dept, Route de Lennik 808, B1070 Bruxelles, Belgium, Fax: 3225554411

Keywords: Asbestos fibres, asbestos bodies, bronchoalveolar lavage analysis, electron microscopy, light microscopy minerological analysis

This report of the European Respiratory Society (ERS) was endorsed by the ERS Executive Committee on March 1, 1998.

The European Respiratory Society provided financial support to the Working Group.

\section{CONTENTS}

Definitions of control populations and reference levels (P. Brochard, E. Monsó, A. Gibbs, J-C. Pairon,

P. Dumortier).

Sampling, preparations and analytical techniques

(P. Dumortier, M.A. Billon-Galland,

A. Tossavainen)

Sampling ..... 1418

Lung tissue. 1419

Sample preparation 1419

Asbestos bodies and fibre counting ........................1419

Expression of results ..........................................1420

Reproducibility and compatibility of results ..........1420

Asbestos fibres in lung tissues in different pathologies (A. Gibbs, A. Karjalainen, S. Anttila,

M.A. Billon-Galland, M. Fischer, K. Rödelsperger) .1420

Pleural plaques .................................................... 1420

Diffuse pleural fibrosis ............................................1421

Asbestos comprises a group of six hydrated silicate minerals capable of forming very thin fibres: chrysotile, crocidolite, amosite, anthophyllite, tremolite and actinolite [1]. Chrysotile belongs to the serpentine group and the
Malignant mesothelioma …............................... 1421

Asbestos ..................................................................1421

Lung cancer ............................................................ 1421

Asbestos bodies in lung tissue, bronchoalveolar lavage and sputum (H. Teschler, A. Karjalainen, P. De Vuyst, P. Dumortier, E. Monsó, U. Costabel) ................................................1421

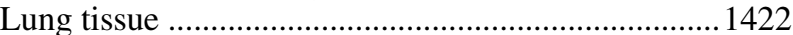

Bronchoalveolar lavage ......................................... 1422

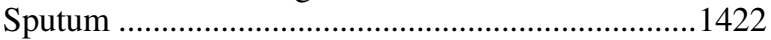

Basis for the interpretation of fibres and asbestos bodies in biological samples

(P. De Vuyst, P. Brochard, A. Gibbs, M. Fischer,

A. Karjalainen, U. Costabel) ......................................1423

Contribution to the assessment of exposure ........... 1423

Contribution to the clinical diagnosis ......................1423

Medicolegal considerations ...................................... 1424

other five to the amphibole group of minerals. Chrysotile fibre bundles split easily and magnesium can be leached under weak acid conditions. These factors may contribute to the lower biopersistence of chrysotile in the lungs. 
Amphiboles are chain silicates with linearly arranged and tightly attached ribbons of silica tetrahedra and they have a high biopersistence.

Amosite, chrysotile and crocidolite have been widely used for industrial purposes. The production of anthophyllite was limited to Finland. Tremolite and actinolite have no industrial applications, but are present as soil constituents in large areas around the Mediterranean Sea (Turkey, Greece, Cyprus, Corsica), in Afghanistan and in New Caledonia. Tremolite fibres may occur in traditional whitewashing or stuccoing material in these areas. Tremolite and actinolite may also be present in chrysotile, talc, dolomite, limestone and vermiculite ores.

The microscopic techniques for analysing the asbestos fibres in lung tissue (LT) and bronchoalveolar lavage (BAL) have provided major information in the understanding of asbestos-related diseases. These analyses are also increasingly applied for clinical work and medicolegal problems. One of the major advantages of these analyses is that they provide an individual estimate of past exposure. A mineralogical analysis of the retained lung fibre burden will be helpful, especially when data on the occupational history are lacking, unreliable or inconclusive.

Differences in sampling, preparation and counting techniques, definitions of reference populations and expression of results have caused major difficulties in comparing results from different laboratories. Reliable interpretation of the results is possible only when one is able to compare the actual result with results obtained in large enough series of controls and disease cases analysed by the same method in the same laboratory.

It appeared important to create a working group of the European laboratories active in this field in order to harmonize the analyses. The participants of the working group are given in table 1 . The work was funded by European Respiratory Society (ERS) and two meetings took place, one in Brussels in December 1994 and the other in
Barcelona in September 1995. The final conclusions were presented at an Assembly Symposium in the ERS Stockholm Congress in September 1996. Five subgroups worked on different topics of the issue. A summary of the working papers of the subgroups and their conclusions is presented in this article. The members of the subgroups are given under the title of each subgroup topic. The key terms and abbreviations used in the article are explained in table 2 .

\section{Definitions of control populations and reference levels}

Asbestos fibres can be detected in the lungs of every individual if a sensitive enough method is used. Therefore laboratories have to define control populations and establish reference values for the methods that they use. These reference values can be used to define whether the observed fibre concentration indicates abnormal retention of mineral fibres and to estimate the probability that the disease case in question can be attributed to past fibre exposure.

Table 2. - Definitions of abbreviations and key terms

$\mathrm{AB}$ Asbestos body: a term used for fibres that have been coated with ferroprotein by macrophages in the lung

BAL Bronchoalveolar lavage

EM Electron microscopy

Fibre In studies of asbestos-related diseases the most commonly used criterion denotes particles with parallel sides and a length to width ratio S 3 [2]. Stricter mineralogical criteria based on the analysis of the crystal structure are sometimes used

LM Light microscopy (optical microscopy)

LT Lung tissue

SEM Scanning electron microscopy

TEM Transmission electron microscopy

$\mu \mathrm{m} \quad$ micrometre $\left(=10^{-6} \mathrm{~m}\right)$

Table 1. - Participants and respective laboratories of the European Respiratory Society working group on guidelines for mineral fibres analysis in biological samples

\begin{tabular}{lll}
\hline Lab & Participants & Location \\
\hline $\mathrm{D}_{1}$ & U. Costabel & Ruhrlandklinik Essen and Institut für Pathologie \\
& H. Teschler & Berupsgenossenschafliche Kliniken Bergmannsheil \\
& M. Fischer & Mesothelium Register, Bochum, Germany \\
$\mathrm{D}_{2}$ & H.J. Woitowitz & Institut und Poliklinik für Arbeits- und Sozialmedizin, Giessen, \\
& K. Rödelsperger & Germany \\
$\mathrm{GB}$ & $\begin{array}{l}\text { A. Gibbs } \\
\text { F.D. Pooley }\end{array}$ & Llandough Hospital University College, Pathology \\
& R. Mitha & Dept, Penarth, and School of Engineering, University of Wales, \\
$\mathrm{B}$ & P. Dumortier & Cardiff, UK \\
& P. De Vuyst & Hôpital Erasme, Unité de Recherche sur la Toxicité des Particules \\
$\mathrm{SP}$ & E. Monsó & Minérales, Brussels, Belgium \\
$\mathrm{F}$ & P. Brochard & Hospital German Trias I Pujol, Servei Pneumologia, Badalona, Spain \\
& J.C. Pairon & Laboratoire d'Étude des Particules Inhalées, Paris, \\
& M.A. Billon-Galland & Service de Pneumologie et ou Pathologie Professionelle, \\
& L. Martinon & Crétail, Université de Bordeaux, France \\
FIN & S. Anttila & Finnish Institute of Occupational Health, Depts of Occupational \\
& A. Karjalainen & Medicine, Epidemiology and Biostatistics, and Industrial Hygiene \\
& A. Tossavainen & and Toxicology, Helsinki, Finland. \\
& T. Tuomi & \\
$\mathrm{I}_{1}$ & F. Mollo & Biomedical Sciences and Human Oncology, Dept of Pathological \\
& P. Burlo & Anatomy and Histopathology, Torino, Italy \\
$\mathrm{I}_{2}$ & L. Paoletti & Istituto Superiore di Sanità, Laboratorio di \\
& M. Falchi & Unltrastructure, Roma, Italy \\
\hline Lab: & abreviation used for laboratories in this article.
\end{tabular}

Lab: abbreviation used for laboratories in this article. 
In relation to mineral fibre concentration in biological samples, the term control population or reference population can be used in the following two different contexts. 1) Epidemiological case-control studies investigate the risk of disease associated with given levels of past exposure. In these studies the control population is defined according to the specific needs of the study. No exclusion from the control population should be made according to the exposure status of the individual. The aim is to acquire a control population which represents the general population of the study area. The exposure levels of the controls and the disease cases are then compared to calculate risk estimates associated with given levels of exposure. Age, sex, smoking, catchment area, etc. may be associated with past exposure and the inclusion criteria of the controls should not cause any such confounding to the results. Cases with the disease under study should of course be excluded from the controls, but not necessarily cases with other diseases. The exclusion criteria depend on the purpose and design of the study. A limited number of such disease-specific case-control studies based on pulmonary fibre analyses has been published and are discussed in section 3 .

2) Laboratories use different kinds of reference populations to describe the typical LT or BAL fibre levels encountered in the variety of exposed and unexposed subpopulations that can be identified in the "general population": a) individuals from rural areas without any asbestos deposits in the soil and with no identifiable occupational exposure; b) individuals from urban areas with no identifiable occupational exposure; c) individuals from areas with asbestos deposits in the soil; d) individuals with domestic or other nonoccupational exposure; and e) individuals with occupational exposure, i.e. exposure related to the industrial use of asbestos at the workplace, ranging from light or moderate exposure to very heavy exposure.

For LT samples, there are, in practice, two ways of acquiring the reference populations under group 2 above, i.e. autopsies or surgical operations. Both of these have one major problem. It is difficult to establish a reliable and thorough exposure history for autopsy cases and for practical reasons the surgical control populations mainly include lung cancer patients, who may have "hidden" low asbestos exposures that are not revealed even by a thorough questionnaire or exposure interview. Most of the participating laboratories have data mainly on the reference populations $2 b$ and $2 \mathrm{e}$ above, and some of them have separate series of autopsy and lung cancer cases. The working group agreed that the ideal situation would be to have both an autopsy case series with less detailed data on past exposure history and a lung cancer case series with good data on past exposure history. An ideal approach would also include reference levels for both smokers and nonsmokers.

The inclusion of individuals into the reference populations under group 2 should be made on the basis of a standardized questionnaire. As regards to absence of occupational exposure, there should be a realistic approach, including both blue-collar workers without probable or possible exposure to asbestos and white-collar workers. Individuals with elevated asbestos fibre levels should not subsequently be excluded from the "unexposed" reference populations if an exposure history justifying exclusion was not revealed by the questionnaire, nor should indi-
Table 3. - Reference values for electron microscopic (TEM) fibre counting used by the participating laboratories

\begin{tabular}{llc}
\hline Lab & \multicolumn{1}{c}{$\begin{array}{c}\text { Fibres of all lengths } \\
\text { fibre.g- }{ }^{-1} \text { dry lung }\end{array}$} & $\begin{array}{c}\text { Fibres Š5 } \mu \mathrm{m} \\
\text { fibre } \cdot{ }^{-1} \text { dry lung }\end{array}$ \\
\hline $\mathrm{D}_{1}$ & \multicolumn{1}{c}{-} & $1.5 \times 10^{6}$ all asbestos \\
$\mathrm{D}_{2}$ & $2.0 \times 10^{6}$ amphiboles & $0.18 \times 10^{6}$ amphiboles \\
& $3.0 \times 10^{6}$ chrysolite & $0.14 \times 10^{6}$ chrysolite \\
& $4.0 \times 10^{6}$ all asbestos & $0.3 \times 10^{6}$ all asbestos \\
$\mathrm{F}$ & $1.0 \times 10^{6}$ amphiboles & - \\
& $10 \times 10^{6}$ all asbestos & - \\
$\mathrm{B}$ & $1.0 \times 10^{6}$ amphiboles & - \\
$\mathrm{GB}$ & $1.0 \times 10^{6}$ amosite & \\
& $1.0 \times 10^{6}$ crocidolite & - \\
& $15 \times 10^{6}$ chrysolite &
\end{tabular}

Lab: abbreviation used for laboratories in this article. TEM: transmission electron microscopy; SEM: scanning electron microscopy.

viduals with high rough markers of exposure (e.g. high asbestos body (AB) counts in BAL or LT) be excluded from reference populations for analysis by transmission or scanning electron microscopy (TEM or SEM). As a detailed exposure history for exclusion of past exposure is impossible to acquire for autopsy cases, it is a reasonable approach to exclude from the unexposed autopsy reference cases with a disease possibly related to asbestos exposure. This does not apply to the group 1 definition of controls above (case-control studies), in which only cases with the disease under study should be excluded from the controls.

In conclusion, given all the various conceptual problems and the various methodologies and selection procedures that can be used to include individuals in the reference population and to establish their past exposure, it is very important to define the kind of reference population to which one refers. Table 3 summarizes the reference values of pulmonary asbestos fibre concentration that are currently used by some of the participating laboratories as the higher limit for urban individuals without occupational exposure to asbestos. The reference values are roughly $1-$ $2 \times 10^{6}$ fibres. ${ }^{-1}$ dry lung for total amphibole fibres and $0.1 \times 10^{6}$ fibres $\cdot g^{-1}$ for amphibole fibres longer than $5 \mu \mathrm{m}$.

\section{Sampling, preparation and analytical techniques}

Fibre analysis of lung samples estimates the fibre burden retained in the lung at the time of sampling, and it integrates both deposition and clearance. An accurate fibre analysis must be based on a representative sample, suit-able and reliable preparation techniques, appropriate in-struments, trained analysts and an appropriate reporting of the results.

\section{Sampling}

Sampling is the first critical step in fibre analysis. For an accurate fibre quantification the sample must be as representative as possible of the whole lung. If the question only concerns the fibre type present, then small or unusual samples may be used. 


\section{Lung tissue}

There are marked variations (up to 10-fold) in the concentration of asbestos fibres between samples from the same lung [3]. The largest distances over which such variations occur are not yet well defined.

The "ideal" LT sample for fibre analysis consists of three pieces of $1-2 \mathrm{~cm}^{3}$, one from the apex of the upper lobe, one from the apex of the lower lobe and one from the base of the lower lobe pooled together. The samples should not contain tumour tissue or pleural fibrosis. The average variability in results from such samples is around $50 \%$, with a maximum of three-fold [3]. It is possible to obtain these ideal samples only by autopsy or pneumonectomy. Samples obtained from lobectomy and large pieces of LT from video-assisted thoracoscopy are "acceptable". In paraffin blocks there is a possibility of contamination of paraffin wax by asbestos fibres [4], but not by AB. Therefore asbestos fibre results based on paraffin blocks should be interpreted with caution. Tumour tissue and tissue are "not acceptable" for fibre quantification since they contain few particles and will result in false-negative counts. Small thoracoscopic LT samples and transbronchial biopsies are not reliable. The particle content of lymph nodes may be influenced by their anatomical location. Parietal pleura must be considered as a very heterogeneous phase. These samples are "not suitable" for routine purposes, but may be used in scientific studies, e.g. when studying the migration of fibres in the human body.

Bronchoalveolar lavage. BAL is much less invasive than thoracoscopy or biopsy and is therefore often performed to evaluate lung fibre burden. A BAL fluid sample can be accepted if it meets the following criteria: it should be performed preferentially in the right middle lobe or in the lingula; the site opposite to the tumour should be sampled, as the tumour may affect injection and recovery; $3 \times 50 \mathrm{~mL}$ or $5 \times 20 \mathrm{~mL}$ of saline must be instilled; recovery must be at least $30 \%$; recovery fluid must not be filtered through gauze; cytological analysis should confirm the alveolar origin of the sample; and analysis should be performed on at least $10 \mathrm{~mL}$, preferably of the second or third fraction as these fractions contain the highest concentration of $\mathrm{AB}$ [5].

If the sample does not meet the above criteria, one could accept a positive result above the reference level, but not a negative result.

\section{Sample preparation}

The ultimate goal of sample preparation is to isolate the fibres from the biological components while modifying them as little as possible to provide the most accurate view of the sample fibre content. Digestion by potassium hydroxide, sodium hypochlorite or formamide, or low temperature ashing are most commonly used. The particle suspension obtained is filtered on membrane filters suitable for examination by light or electron microscopy. The dry to wet weight ratio varies from $5-20 \%$ and should be measured for each sample. The use of a mean conversion factor of 10 for the wet/dry ratio should be avoided. Preparation may introduce modifications to fibre concentra- tion, chemistry or size distribution. Drying the tissue before low-temperature ashing and the uncontrolled use of ultrasound to disperse the residue may break the fibres, resulting in higher counts and smaller sizes. Fibres may be lost during repeated centrifugation.

Special care must be taken to avoid contamination during sampling and preparation. Starch or talc coming from surgical gloves, organic fibres from clothes, particles originating from preparation liquids not filtered before use and crystals precipitated from the reagents used in the digestion of the sample are typical examples of possible contamination. The preparation and storage of asbestoscontaining material samples in the room used for treatment of biological samples should be avoided.

\section{Asbestos bodies and fibre counting}

The advantages and disadvantages of light microscopy (LM) and electron microscopy (EM) are summarized in table 4 . Counting by light microscopy allows the detection of low concentrations but can only detect large fibres and $\mathrm{AB}$. To detect the finest fibres it is necessary to use EM. TEM is preferred because it has a better resolution than SEM, and it is used by more than $90 \%$ of the laboratories.

The lowest concentration detectable by each method is described by its analytical sensitivity or detection limit. Analytical sensitivity corresponds to the calculated concentration equivalent to observing one fibre or one $\mathrm{AB}$ in the analysis. The detection limit is defined as the upper limit of the one-sided Poisson 95\% confidence interval for a zero count. It is equivalent to 2.99 times the analytical sensitivity. It is important to know the detection limit, as a method with a high detection limit may give negative results even in individuals with an important exposure.

The EM instruments are usually equipped with additional devices to determine the chemical composition and the crystal structure of the fibre. It is possible to identify the different asbestos fibre types and nonasbestos fibre

Table 4. - Main advantages and disadvantages of electron microscopy and light microscopy in (asbestos) fibre counting in bronchoalveolar lavage and tissue samples

\begin{tabular}{|c|c|c|}
\hline Method & Advantages & Disadvantages \\
\hline $\begin{array}{l}\text { Light } \\
\text { microscopy }\end{array}$ & $\begin{array}{l}\text { Quick and easy } \\
\text { Inexpensive } \\
\text { Possible to detect low } \\
\text { concentrations } \\
\left(0.1 \mathrm{AB} \cdot \mathrm{mL}^{-1} \text { or }\right. \\
30 \mathrm{AB} \cdot \mathrm{g}-1) \text { with a } \\
\text { reasonable amount } \\
\text { of labour }\end{array}$ & $\begin{array}{l}\text { Low resolution (only } \\
\text { fibres thicker than } 0.2 \\
\mu \text { m can be detected). } \\
\text { Consequently limited } \\
\text { only to AB and large } \\
\text { fibres } \\
\text { Does not enable } \\
\text { identification of the } \\
\text { fibre type }\end{array}$ \\
\hline $\begin{array}{l}\text { Electron } \\
\text { microscopy }\end{array}$ & $\begin{array}{l}\text { High resolution (fibres } \\
\text { as thin as } 0.01 \mu \mathrm{m} \\
\text { can be detected with } \\
\text { TEM). Consequently, } \\
\text { all fibres are detected. } \\
\text { Enables identification } \\
\text { of the fibre type and } \\
\text { measurement of the } \\
\text { fibre dimensions }\end{array}$ & $\begin{array}{l}\text { Time consuming } \\
\text { Expensive } \\
\text { Detection of } \\
\text { concentrations below } 50 \\
\text { fibres } \cdot \mathrm{mL}^{-1} \text { or } 50,000 \\
\text { fibres } \cdot \mathrm{g}^{-1} \text { is very time } \\
\text { consuming }\end{array}$ \\
\hline
\end{tabular}

AB: asbestos bodies; TEM: transmission electron microscopy. 
types with comparison to reference data from standard materials. Nonasbestos fibres may represent an important proportion of the total fibre burden. The most common ones are mullite, rutile, silica, aluminium oxide, mica and kaolin [3]. Their concentration is often greater than that of asbestos, especially in samples with low or intermediate asbestos fibre concentrations. EM enables their discrimination from asbestos fibres, but LM does not.

\section{Expression of results}

Analytical results are currently expressed as $\mathrm{AB}$ or fibres $\cdot \mathrm{mL}^{-1} \mathrm{BAL}$, or AB or fibres $\cdot \mathrm{g}^{-1}$ dry LT. Expression of results as $\mathrm{AB}$ or fibres. $\mathrm{g}^{-1}$ wet $\mathrm{LT}$, or $\mathrm{AB}$ or fibres $\cdot \mathrm{cm}^{-3} \mathrm{LT}$ should be avoided. For negative results, the analytical sensitivity of the analysis must be reported. Fibre types should be reported and asbestos and nonasbestos fibre concentrations should be reported separately. At least for scientific reporting, the geometric mean of the fibre length, diameter and length : diameter ratio (aspect ratio) should be given.

\section{Reproducibility and comparability of results}

The question of reproducibility of the results is resolved by intralaboratory tests that should give consistent results for repeated analysis of the same sample. Regarding interlaboratory comparisons, figure 1 shows that in a comparison of three experienced laboratories, the AB counts in LT could be reliably compared. Similarly, three independent large studies comparing BAL and LT AB concentrations resulted in very similar regression equations [6]. For EM counting of asbestos fibres, figure 2 summarizes the results of an interlaboratory comparison of five European laboratories in TEM fibre counting on homogenized lung samples [7]. There are obvious interlaboratory differences. Nevertheless, samples with low counts were consistently reported as low and samples with high counts as high.

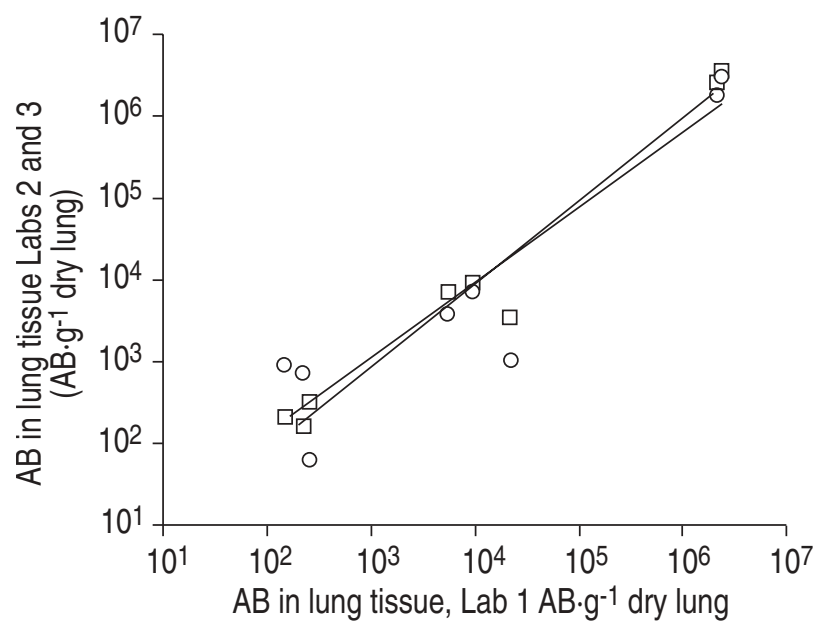

Fig. 1. - Interlaboratory comparison of asbestos body $(\mathrm{AB})$ concentrations in lung tissue by light microscopy in samples analysed by three European laboratories (Labs 1-3). $\mathrm{r}^{2}$ : correlation according to linear regression analysis. $\square$ : Lab 2 versus $\mathrm{Lab} 1, \mathrm{r}^{2}=0.965$; ○: Lab 3 versus Lab 1, r2: 0.855. (P. Dumortier, F.D. Pooley, P. Brochard, unpublished data).

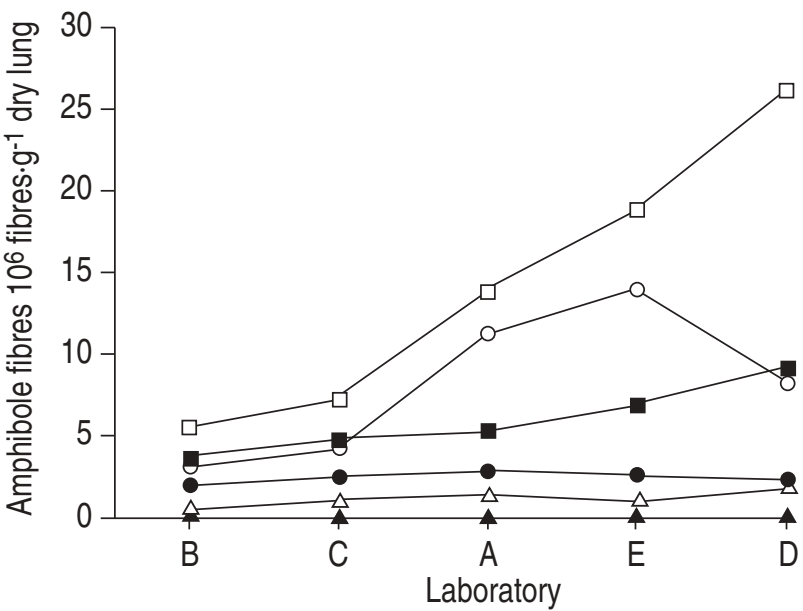

Fig. 2. - Interlaboratory comparison of amphibole asbestos fibre counting in lung tissue with transmission electron microscopy by five European laboratories. $\square$ : sample 1; O : sample 2; ý : sample 3; sample 4; • : sample 5; $\boldsymbol{\wedge}$ : sample 6.

In conclusion, mineralogical analysis assesses the fibre burden at the time of sampling, but gives no information on cleared fibres. This is important to remember that chrysolite has a lower biopersistence than amphiboles. The choice and quality of the sample are critical and these analyses must be performed by specialized laboratories with a comprehensive knowledge of the techniques. Techniques must always be the same, be described clearly and give reproducible results. In comparison to routine analysis of asbestos bodies by LM, results obtained by more sophisticated techniques (e.g. EM) are subject to higher variability between laboratories and their interlaboratory comparison will be more difficult.

\section{Asbestos fibres in lung tissues in different pathologies}

It is very important to realize that there are different dose-response relationships between lung parenchyma and pleura in response to asbestos exposure and there is a gradient of fibre levels for the various asbestos-related diseases. The highest median pulmonary fibre levels are found in asbestosis, while lower levels may occur in mesothelioma and the lowest levels in pleural plaques.

\section{Pleural plaques}

Only a few studies have analysed lung asbestos fibre burdens in relation to pleural plaques. In a study of 25 plaque cases, $\mathrm{AB}$ were found in digests from all of the cases and the concentration exceeded the normal range in $56 \%$ [8]. No differences in the frequency of known or presumed exposure to asbestos were found between the plaque cases and controls, as determined by information obtained on occupation from chart review. GYLSETH et al. [9] found a median concentration (SEM) of 2.2 (range $0.1-13$ ) $\times 10^{6}$ uncoated fibres.g- ${ }^{-1}$ dry LT in 14 cases of pleural plaques, compared with $0.6 \times 10^{6}$ fibres in 12 controls. GIBBS et al. [10] found elevated amphibole asbestos fibre levels in six out of 22 subjects with pleural plaques, but found no correlation between fibre levels and the number and size of 
plaques. In a Finnish study of 300 male urban autopsy cases, asbestos fibre counts exceeding the reference value for occupational exposure $\left(>1.0 \times 10^{6}\right.$ amphibole fibres. $\mathrm{g}^{-1}$ dry LT, SEM) were found in $24 \%$ of cases with pleural plaques. The median asbestos fibre count was slightly higher among cases with widespread plaques than among those without plaques, but remained below the reference value of occupational exposure in both of these groups (0.57 and $0.16 \times 10^{6}$ amphibole fibres. $\mathrm{g}^{-1}$ dry LT) [11]. A French study found an elevated BAL AB count in $40 \%$ of cases with pleural plaques, but no correlation between the extent of plaques and the BAL AB count [12].

In summary, in subjects with pleural plaques but without asbestosis, which are the majority of cases seen in routine post mortem, amphibole but not chrysotile fibre levels are slightly raised in about half of the cases in the published studies. There are various possible explanations for the results concerning the subjects with plaques but without an elevated fibre level: 1) the plaques are not related to asbestos exposure; 2) they are related to chrysotile but because of the different clearance characteristics the chrysotile fibres are eliminated and not detected (there is very little epidemiological evidence for this hypothesis); 3 ) the exposure is so light that it is not reflected in elevated fibre burdens; and 4) the fibres have migrated to the pleura and no longer persist in lung parenchyma [13].

\section{Diffuse pleural fibrosis}

There are very few publications concerning lung tissue fibre levels in subjects with asbestos-related diffuse pleural fibrosis. In a study of 13 subjects, samples from central and subpleural LT and pleura were analysed by TEM [14]. No significant difference between the central and subpleural zones was found, but the amphibole levels were higher in 11 of the cases than in controls from the same laboratory. In general, the levels were higher than those observed in cases with pleural plaques but lower than those observed in cases of asbestosis.

\section{Malignant mesothelioma}

Several studies have been published on the mineral fibre content of LT from subjects with mesothelioma. In those with mesothelioma but without pathological changes of asbestosis, which is a frequent occurrence, studies generally have shown elevated levels of amphibole but not chrysotile fibres compared with controls and cases with pleural plaques, but below those associated with asbestosis [3, 15]. Raised levels of amphibole fibres have also been found in the LT of subjects with mesothelioma who were considered epidemiologically to have been predominantly exposed to chrysotile, e.g. tremolite in Québec chrysotile miners and millers [16] or crocidolite in Rochdale textile workers [17].

In case-control studies, statistically increased risks of mesothelioma have been associated with amphibole fibre levels exceeding $1.0 \times 10^{6}$ fibres $(>1 \mu \mathrm{m}) \cdot \mathrm{g}^{-1}$ dry lung, $0.1-$ $0.2 \times 10^{6}$ fibres $(>5 \mu \mathrm{m}) \cdot \mathrm{g}^{-1}$ dry lung or $0.3-1.0 \times 10^{6}$ fibres $(>10 \mu \mathrm{m}) \cdot \mathrm{g}^{-1}$ dry lung [18-20].

\section{Asbestosis}

The published studies have generally demonstrated much higher amphibole asbestos fibre burdens in subjects with asbestosis than in subjects with asbestos-related pleural disorders, and progressively increased amphibole fibre burdens with increasing severity of fibrosis [15, 21, 22]. In one laboratory the mean fibre burden ranged from $130 \times$ $10^{6}$ fibres $\cdot g^{-1}$ dry lung (TEM) in mild histological asbestosis to nearly $2000 \times 10^{6}$ fibres $\cdot g^{-1}$ dry lung in severe asbestosis ([21] A. Gibbs, personal communication). Another laboratory found that the geometric mean concentration of asbestos fibres (TEM, fibres. ${ }^{-1}$ dry lung) in 38 patients with asbestosis was $23 \times 10^{6}$ for fibres shorter than $5 \mu \mathrm{m}$, $5.9 \times 10^{6}$ for fibres $5-9.9 \mu \mathrm{m}$ in length and $1.7 \times 10^{6}$ for fibres Š $10 \mu \mathrm{m}$ in length [23]. These levels were 20-140 times higher than in the control population, i.e. males who died from accidental deaths or myocardial infarction in the same area as the asbestosis cases. There is a need for further studies on the effect of fibre size and mass distributions on fibrosis. There is also experimental evidence to indicate that the presence of other minerals may influence the effect of asbestos on the development of fibrosis, but this has not been addressed at all in human studies.

\section{Lung cancer}

Cumulative exposure to asbestos and the presence of fibrosis (asbestosis) are closely related. In epidemiological settings, increased risks of lung cancer have usually been associated with exposure levels that are high enough to cause asbestosis, and it is generally accepted that the risk of lung cancer is increased when asbestosis is present $[24,25]$. Some recent studies have indicated that the risk may even be increased among exposed workers without asbestosis [26, 27]. The fibre levels found in cases of asbestos-related lung cancer depend on the criteria used for the attribution.

In conclusion, mineral fibre analysis has provided very useful information in helping to understand the dose responses in various asbestos-related diseases. It has also been the tool which first indicated that contaminants of the suspected mineral rather than the mineral itself might have been the pathogenic agent. Interpretation of the results of mineral fibre levels in particular cases will vary according to the disease considered. Again, one has to bear in mind that interlaboratory comparisons of EM fibre levels in the different disease categories should be interpreted with cau-tion.

\section{Asbestos bodies in lung tissue, bronchoalveolar lavage and sputum}

$\mathrm{AB}$ are formed on inhaled asbestos fibres deposited for at least 4-6 months in the lower respiratory tract. Only a minority of the total inhaled fibres become coated to form AB. Their occurrence in the lungs is closely associated with the concentration of long amphibole fibres, and fibres shorter than $10 \mu \mathrm{m}$ rarely become coated [22, 28]. Elevated concentrations of $\mathrm{AB}$ formed on chrysotile fibres can, however, be found in the lungs of workers with a heavy exposure to chrysotile [29]. As such bodies can also form on inorganic fibres other than asbestos, the term ferruginous body is sometimes used. The coated fibres other 
than asbestos are, however, of minor value, since $\mathrm{AB}$ usually account for $90 \%$ or more of all coated fibres [28-30]. In foundry workers, nonasbestos bodies may constitute a high proportion of all ferruginous bodies, and workers from ferrous industries seem to have a larger than average proportion of coated asbestos fibres [3, 31]. There is a well-established statistical correlation between the AB burden and the total asbestos fibre burden in the lungs. Much of the variation at the individual level is, however, hidden behind this statistical correlation. This variation is due to the various factors briefly described above. Therefore the $\mathrm{AB}$ burden in the lungs is only a coarse estimate of the total asbestos fibre burden in the lungs.

Lung tissue samples allow quantification of all $A B$ from the alveolar airspace and interstitial compartment. Quantification of AB in LT can only be performed after autopsy or requires a surgical lung biopsy. In order to avoid this invasive and potentially risky surgical procedure, attention has turned during the last two decades to the quantification of $\mathrm{AB}$ in $\mathrm{BAL}$ or sputum specimens. Only $\mathrm{AB}$ from the alveolar airspace compartment are selectively accessible by BAL and sputum samples.

\section{Lung tissue}

Quantitative LT analysis is the "gold standard" by which to quantitate lung $\mathrm{AB}$ concentration. There is a relationship between the number of $A B$ in iron-stained histological sections and the $\mathrm{AB}$ concentration in digested LT [32]. Counting $\mathrm{AB}$ in iron-stained tissue sections and counting $\mathrm{AB}$ in digested LT samples are the methods that are most frequently applied to assess the $\mathrm{AB}$ content of the lungs. Values $>1000 \mathrm{AB} \cdot \mathrm{g}^{-1}$ dry LT and 1-2 AB-tissue section $^{-1}$ are usually considered as indicative of nontrivial (usually occupational) exposure [5, 15, 32-34]. The corresponding limits may be somewhat higher in areas where exposure to long amphiboles is common, e.g. anthophyllite in Finland $[6,35]$.

The concentration of $\mathrm{AB}$ within the same lung varies up to 10 -fold, but there is no consensus on whether the variation is systematic between the upper and lower lobes or the central and peripheral areas [3,36]. The variation may be partly related to the low precision of the analytical methods or counting statistics.

\section{Bronchoalveolar lavage}

BAL is by far less invasive than open lung biopsy, but enables the collection of $\mathrm{AB}$ from the intra-alveolar space and the conducting airways. Over the last few years several studies have quantified $\mathrm{AB}$ in $\mathrm{BAL}$ and correlated these with exposure history, specific occupation, different asbestos-related diseases, radiological findings, and the degree of functional impairment.

$\mathrm{AB}$ are rarely found in BAL of control subjects without occupational or specific environmental exposure, and if so, are usually in concentrations below $0.5-1.0 \mathrm{AB} \cdot \mathrm{mL}^{-1}$. In a German study of 371 patients with no evidence of increased exposure to asbestos by questionnaire and occupational history, $99 \%$ had concentrations $<0.5 \mathrm{AB} \cdot \mathrm{mL}^{-1}$ in $\mathrm{BAL}$ [37]. In Belgium, BAL $\mathrm{AB}$ concentrations $>1.0$ $\mathrm{AB} \cdot \mathrm{mL}^{-1}$ were found in $6.0 \%$ of 115 white-collar and $18 \%$ of 117 blue-collar workers without known occupational exposure to asbestos [38]. Similar results have been pub- lished in several other large series of patients $[15,39,40]$. The concentration of $\mathrm{AB}$ in $\mathrm{BAL}$ correlates roughly with the past cumulative exposure to asbestos. It can disclose, for example, important indirect bystander exposure, which may be missed in questionnaires or exposure interviews, or it can be useful when questionnaire or interview data are unavailable, unreliable or difficult to quantify (e.g. construction work); however, a negative BAL AB count does not rule out significant exposure, especially among workers exposed to chrysotile asbestos.

Several studies have investigated the correlation between $\mathrm{BAL} \mathrm{AB}$ concentration and lung parenchymal $\mathrm{AB}$ or asbestos fibre concentration $[5,6,37,41]$. The regression equations predicting the underlying parenchymal concentrations from the concentration of $\mathrm{AB}$ in $\mathrm{BAL}$ were very similar [6]. A concentration of $>1 \mathrm{AB} \cdot \mathrm{mL}^{-1}$ was associated with a high probability of having more than 1000 $\mathrm{AB} \cdot \mathrm{g}^{-1}$ dry lung. In two studies the total amphibole fibre bur- den in lung parenchyma was assessed with EM and was shown to correlate with the BAL AB content $[6,42]$. The chrysotile content in lung parenchyma did not correlate with the BAL AB content [42].

Concerning the various asbestos-related diseases, a BAL $\mathrm{AB}$ count exceeding $0.1 \mathrm{AB} \cdot \mathrm{mL}^{-1}$ was found in $98 \%$ of Belgian patients with asbestosis, $95 \%$ of those with benign pleural disease and $75 \%$ of those with malignant mesothelioma [38]. A considerable overlap in AB counts was found between the different disease categories and patients without an asbestos-related disease. Median values were $121 \mathrm{AB} \cdot \mathrm{mL}^{-1}$ in asbestosis, $5 \mathrm{AB} \cdot \mathrm{mL}^{-1}$ in benign pleural disease and $4 \mathrm{AB} \cdot \mathrm{mL}^{-1}$ in exposed workers without evidence of an asbestos-related disease. Similar results have been published in smaller series of patients [39, 43, 44].

While there is a good overall correlation between the $\mathrm{AB}$ counts in BAL and lung parenchyma, it is not clear to what extent the underlying variation is due to: 1) differences between alveolar (measurable by BAL) and total amounts of $\mathrm{AB}$ (measurable by tissue digestion); 2) anatomic variation between BAL and lung parenchymal sampling; or 3) variations in the lavage and counting techniques. It was recently found that the BAL $\mathrm{AB}$ counts were twice as high in the lower lobes than in the upper lobes, whereas there were no significant differences between corresponding sampling sites in the right and the left lung [36]. Meanwhile, it has been shown in two studies that there is generally a good within-laboratory reproducibility for double counting or repeated lavage, especially for clearly elevated counts $[38,43]$.

\section{Sputum}

Collection of sputum is simpler, less invasive and less expensive than open lung biopsy or BAL. AB in sputum are a highly specific marker for past asbestos exposure, since no false-positive samples were found in more than 11,000 sputum samples from patients from the general population in USA [45]. However, sputum AB content is a very insensitive measure of lung asbestos fibre burden. TESCHLER et al. [46] found that sputum samples were positive in only 28,43 and $79 \%$ of individuals with 1-4.9, 5-49.9 and more than $50 \mathrm{AB} \cdot \mathrm{mL}^{-1}$ in BAL, respectively. The sputum samples were negative in $33 \%$ of heavily exposed, $68 \%$ of moderately exposed and $45 \%$ of occasionally exposed subjects with $\mathrm{AB}$ in BAL samples. 
A high variation in $\mathrm{AB}$ counts has been demonstrated on sequential sputum samples, and analysis of pooled daily expectoration of sputum may yield fewer false-negative results [46, 47], but even with five specimens the sensitivity remained quite low [48]. At least three studies comparing $\mathrm{LT}$ and sputum $\mathrm{AB}$ contents indicated that $\mathrm{AB}$ do not appear in sputum below a lung burden in the order of $1000 \mathrm{AB} \cdot \mathrm{g}^{-1}$ wet lung or more (approximately 10,000 $A B \cdot g^{-1}$ dry lung) [46]. A negative sputum sample for $A B$ does not exclude the possibility of a high lung AB burden. Sputum sampling may be useful as a tool in surveys of populations with no definite exposure according to questionnaire data, in order to detect individuals with significant lung retention of amphiboles or $\mathrm{AB}$. The noninvasive nature of this sampling method may be interesting from the point of view of occupational medicine. However, the poor sensitivity of the method must be kept in mind in both of the afore-mentioned possible practical applications.

In conclusion, in clinical routines, analysis of the concentration of asbestos bodies in LT by LM is recommended to estimate the total lung amphibole burden if the history of asbestos exposure is lacking or inconclusive, and if LT is available from either autopsy or curative surgery. Asbestos body counts above $1000 \mathrm{AB} \cdot \mathrm{g}^{-1}$ dry lung indicate nontrivial exposure. Otherwise, BAL specimens can be used to estimate lung retention of asbestos bodies and past exposure in cases with lacking or inconclusive exposure history. Concentrations above $1 \mathrm{AB} \cdot \mathrm{mL}^{-1}$ in BAL are associated with a high probability of $>1000 \mathrm{AB} \cdot \mathrm{g}^{-1}$ dry lung and $1 \times 10^{6}$ amphibole fibres. $\mathrm{g}^{-1}$ dry lung. Sputum analysis is much less sensitive than BAL in estimating lung $\mathrm{AB}$ burden, but a positive sputum sample predicts a high lung burden.

\section{Basis for the interpretation of fibres and asbestos-bod- ies in biological samples}

Asbestos fibres and $\mathrm{AB}$ can be found in the lungs of almost every person, and for reliable interpretation of quantitative results it is crucial that standardized methodologies have been used (see section 2) and that comparisons can be made to an adequate reference population analysed by the same laboratory (see section 1). Furthermore, it is important to understand that lung fibre or $\mathrm{AB}$ content at the time of analysis is influenced by complex phenomena of exposure (type, concentration and dimensions of airborne fibres), deposition and clearance. The cumulative exposure and the time elapsed since exposure will influence the LT and BAL asbestos fibre and $\mathrm{AB}$ concentration (see sections 3 and 4). It is especially important to remember the much faster clearance of chrysotile fibres compared to amphiboles, and the fact that the $\mathrm{AB}$ content in BAL or LT mainly reflects the concentration of long amphiboles in the lung parenchyma, when interpreting mineral fibre analyses.

Several European and American laboratories consider that concentrations exceeding the following values are indicative of nontrivial exposure to asbestos: $1 \mathrm{AB} \cdot \mathrm{mL}^{-1}$ in BAL, $1000 \mathrm{AB} \cdot \mathrm{g}^{-1}$ dry lung tissue, $1 \times 10^{6}$ amphibole fibres $(>1 \mu \mathrm{m}) \cdot \mathrm{g}^{-1}$ dry lung tissue and $0.1 \times 10^{6}$ amphibole fibres $(>5 \mu \mathrm{m}) \cdot \mathrm{g}^{-1}$ dry lung tissue (see sections 1 and 4 for details). These are relative and arbitrary limits which refer to levels that are seldom exceeded in lifetime white-collar workers. When compared against work histories, there are large overlaps in the fibre or $\mathrm{AB}$ counts between individuals classified as exposed and unexposed to asbestos. However, concentrations found in individuals with high cumulative exposures (e.g. asbestos sprayers) largely exceed the above-mentioned values and can reach thousands of $\mathrm{AB} \cdot \mathrm{mL}^{-1}$ in BAL and billions of amphibole fibres. $\mathrm{g}^{-1}$ dry lung in severe asbestosis. It is usually easy to interpret high concentrations (e.g. $50 \times 10^{6}$ fibres $\cdot \mathrm{g}^{-1}$ dry LT), although a short time interval between the last exposure and the sampling can be a problem when interpreting results from TEM or SEM analysis in BAL samples. In general, it is less easy to interpret values around the refer-

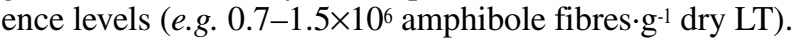

The most important rule for interpretation is the following: an elevated concentration of fibres or $\mathrm{AB}$ in $\mathrm{BAL}$ or LT indicates an elevated retention of fibres compared with the unexposed reference population. This usually reflects an occupational exposure, but it is not proof of disease. For practical reasons it is important to assess the occupational history of the patient at an early stage of the clinical investigations. This ensures that if mineralogical analyses are needed the samples can be taken during normal diagnostic or curative procedures. Invasive procedures, especially thoracotomy, should not be performed merely to collect samples for mineralogical analyses. The collection of large LT specimens should be restricted to autopsies and to patients with a clinical indication for operation.

\section{Contribution to the assessment of exposure}

Mineralogical analysis is one exposure estimate among many others, including occupational history interviews, standardized questionnaires and industrial hygiene measurements. A mineralogical analysis contributes to the assessment of the intensity of past exposure, especially when data from other sources are unavailable, unreliable or difficult to interpret quantitatively. It can, for example, reveal an important indirect exposure as a bystander, which was not recalled or comprehended by the patient, or it may reveal an important environmental exposure during childhood in individuals from areas where such exposures may occur. Positive results can confirm past exposures but negative ones cannot overrule a clear exposure history, especially where exposure to chrysotile is concerned. In surgically treated lung cancer patients, systematic counting of $\mathrm{AB}$ in the surgical lung specimens can be used to detect cases that require careful evaluation of the occupational history, the histological findings or the lung fibre content by EM analysis [49].

\section{Contribution to the clinical diagnosis}

Inhalation of asbestos is associated with a large variety of diseases and abnormal radiographic findings of the lung parenchyma and pleura. The diseases may be more or less specific, influenced by the cumulative exposure and therefore associated with different levels of lung fibre burdens (table 5 and section 3 ). 
Table 5. - Asbestos-related diseases of the lung and pleura according to their specificity in relation to asbestos exposure

\begin{tabular}{lll}
\hline Site & Nonspecific & Specific \\
\hline Lung & $\begin{array}{l}\text { Lung cancer } \\
\text { Diffuse interstitial } \\
\text { pulmonary disease* }\end{array}$ & Asbestosis* \\
Pleura & $\begin{array}{l}\text { Benign pleural effusion } \\
\text { Diffuse pleural thickening }\end{array}$ & $\begin{array}{l}\text { Mesothelioma } \\
\text { Hyaline or calcified } \\
\text { bilateral-pleural plaques }\end{array}$ \\
& Rounded atelectasis & \\
\hline
\end{tabular}

*: Asbestosis refers to the classical definition of asbestos-induced pulmonary fibrosis, which is a pathologically well-defined specific asbestos-related disease [33]. The differential diagnosis between asbestosis and other, nonspecific diffuse pulmonary fibrosis is, however, not possible only on the basis of chest radiography or computed tomography.

Specific diseases. Asbestosis can be pathologically diagnosed by the detection of numerous $\mathrm{AB}$ in histological LT sections together with diffuse pulmonary fibrosis [33]. Asbestosis is associated with high fibre and $\mathrm{AB}$ burdens in LT and BAL. If only a few AB are detected, an EM analysis should be performed. A fibre burden within the normal range of the unexposed reference population together with no obvious history of asbestos exposure is a strong argument against asbestosis. The differential diagnosis bet-ween asbestosis and other diffuse lung fibrosis is the only situation where $\mathrm{AB}$ or fibre analysis may help in making a medical diagnosis and affect the choice of therapy. In many countries the epidemic of asbestosis is gradually shifting to older age categories and milder diseases. Mean-while, the incidence of idiopathic pulmonary fibrosis seems to be increasing [50]. It is to be expected that problems in the differential diagnosis will become more frequent.

The diagnosis of mesothelioma or bilateral pleural plaques is made on a clinicopathological basis. Mineral analysis will sometimes help in ascribing the aetiology of the disease (e.g. fibre type), although both of these diseases can be associated with asbestos exposure, even at low lung fibre burdens (see section 3). It must be stressed that BAL and LT analyses are markers of alveolar and parenchymal retention of fibres, but do not reflect directly the accumulation of fibres in the parietal pleura [13].

Nonspecific or less specific diseases. Benign pleural effusion and diffuse pleural thickening can have many causes (certain drugs, infections, connective tissue disorders, etc.). The diagnosis of an asbestos-related case is made on an exclusion basis. Unilateral or atypical pleural calcifications can also have causes other than asbestos (trauma, tuberculosis, etc.). The clinical diagnosis and treatment of lung cancer is not influenced by mineral analyses. Rounded atelectasis may be associated with various pulmonary fibre concentrations [51]. In all of these nonspecific asbestos-related diseases a mineral analysis will help only in aetiological inferences.

\section{Medicolegal considerations}

The medico-legal aspects of asbestos-related diseases depend on national (or local) compensation systems. Never- theless, a few rules can be stated.

1) A fibre level above the reference value is not proof of disease, but an indication of exposure. Many cases are notified for compensation simply on the basis of an elevated $\mathrm{AB}$ content in BAL without any radiological or clinical manifestations of an asbestos-related disease and are finally rejected.

2) If the occupational exposure is obvious and the lesion is specific (table 5), a mineralogical analysis is usually not required. Conversely, in nonspecific conditions or with unclear exposure histories, the recognition of an asbestos-related case will be influenced by an elevated fibre or $\mathrm{AB}$ count. The greater the concentration of fibres or $\mathrm{AB}$ the greater the probability of the aetiological role of asbestos.

3) Compensation of an occupational disease is legally related to exposure during employment. In some cases the identification of tremolite by EM may point towards a nonoccupational disease in individuals originating from areas with environmental exposure to tremolite [52]

4) One of the greatest problems to be expected is the role of BAL or LT AB or fibre analyses in the recognition of asbestos-related lung cancer. The problem is epidemiologically controversial and there is no general scientific agreement on the issue (see section 3), but some practical guidelines have been proposed [53].

In conclusion, standardized methodologies, adequate reference populations, as well as a comprehensive understanding of the factors affecting the retention, deposition and clearance of fibres in the lungs and of the different dose-responses of the various asbestos-related diseases, are crucial for the interpretation of the results of LT and BAL mineralogical analyses. Such results help in ascribing the asbestos aetiology, especially in cases where the exposure data from other sources are unavailable, unreliable or quantitatively unclear. A high fibre burden indicates exposure but is not proof of disease. A negative result is not proof of the absence of significant exposure, especially when chrysotile is concerned, but the exposure history should be evaluated carefully. Invasive procedures, especially thoracotomy, should not be used to collect samples for mineralogical analysis if there is no clinical indication for the procedure.

\section{References}

1. Pooley FD. Asbestos mineralogy. In: Antman K, Aisner J, eds. Asbestos-related Malignancy. Boston, Grune \& Stratton, 1987; pp. 3-27.

2. WHO. Asbestos and other natural mineral fibres. IPCS (International Programme for Chemical Safety) Environmental Health Criteria 53. Geneva, WHO, 1986.

3. Gibbs AR, Pooley FD. Analysis and interpretation of inorganic mineral fibres in "lung" tissues. Thorax 1996; 51: 327-334.

4. Gibbs AR, Pooley FD. Toxicology elsewhere. Bits and pieces: asbestos contamination in paraffin tissue blocks. Hum Exp Toxicol 1996; 15: 85-86.

5. Sebastien P, Armstrong B, Monchaux G, Bignon J. Asbestos bodies in bronchoalveolar lavage fluid and in lung parenchyma. Am Rev Respir Dis 1988; 137: 75-78.

6. Karjalainen A, Piipari R, Mäntylä T, et al. Asbestos bodies in bronchoalveolar lavage in relation to asbestos bodies and asbestos fibers in lung parenchyma. Eur Respir $J$ 
1996; 9: 1000-1005.

7. Tossavainen A, ed. Final Report. Measurement and testing programme project MAT1-CT94-0072 - reference materials for the analysis of asbestos fibres in lung tissue. Finnish Institute of Occupational Health, 1996.

8. Wain SL, Roggli VL, Foster WL. Parietal pleural plaques, asbestos bodies, and neoplasia. A clinical, pathologic, and roentgenographic correlation of 25 consecutive cases. Chest 1984; 86: 707-713.

9. Gylseth B, Mowé G, Skaug V, Wannag A. Inorganic fibers in lung tissue from patients with pleural plaques or malignant mesothelioma. Scand J Work Environ Health 1981; 7: 109-113.

10. Gibbs AR, Pooley FD, Griffiths DM. Lung fibrous content of subjects with pleural plaques. Eur Respir J 1994; 7: Suppl. 18, 425s.

11. Karjalainen A, Karhunen P, Lalu K, Penttilä A, Kyyrönen $\mathrm{P}$, Tossavainen A. Pleural plaques and exposure to mineral fibres in a male urban necropsy population. Oсcup Environ Med 1994; 51: 456-460.

12. Orlowski E, Pairon JC, Ameille J, et al. Pleural plaques, asbestos exposure, and asbestos bodies in bronchoalveolar lavage. Am J Ind Med 1994; 26: 349-358.

13. Boutin C, Dumortier P, Rey F, Viallat JR, De Vuyst P. Black spots concentrate oncogenic asbestos fibers in the parietal pleura. Am J Respir Crit Care Med 1996; 153: 444-449.

14. Gibbs AR, Stephens M, Griffiths DM, Blight BJN, Pooley FD. Fibre distribution in the lungs and pleura of subjects with asbestos related diffuse pleural fibrosis. $\mathrm{Br} \mathrm{J}$ Ind Med 1991; 48: 762-770.

15. Roggli VL, Pratt PC, Brody AR. Asbestos content in lung tissue in asbestos associated disease: a study of 110 cases. Br J Ind Med 1986; 43: 18-29.

16. Dufresne A, Bégin R, Churg A, Massé S. Mineral fiber content of lungs in patients with mesothelioma seeking compensation in Québec. Am J Respir Crit Care Med 1996; 153: 711-718

17. Wagner JC, Berry G, Pooley FD. Mesothelioma and asbestos type in asbestos textile workers: a study of lung contents. Br Med J 1982; 285: 603-606.

18. Tuomi T, Huuskonen M, Virtamo M, et al. Relative risk of mesothelioma associated with different levels of exposure to asbestos. Scand J Work Environ Health 1991; 17: 404-408.

19. Rödelsperger K, Woitowitz HJ. Airborne fibre concentrations and lung burden compared to the tumor response in rats and humans exposed to asbestos. Ann Occup Hyg 1995; 39: 715-725.

20. Rogers AJ, Leigh J, Berry G, Ferguson DA, Mulder HB, Ackad M. Relationship between lung asbestos fiber type and concentration and relative risk of mesothelioma. Cancer 1991; 67: 1912-1920.

21. Gibbs AR, Gardner MJ, Pooley FD, Griffiths DM, Blight B, Wagner JC. Fibre levels and disease in workers from a factory using predominantly amosite. Environ Health Perspect 1994; 102: (Suppl. 5), 261-263.

22. Albin M, Johansson L, Pooley FD, Jakobsson K, Attewell R, Mitha R. Mineral fibres, fibrosis, and asbestos bodies in lung tissue from deceased asbestos cement workers. $\mathrm{Br}$ J Ind Med 1990; 47: 767-774.

23. Dufresne A, Bégin R, Massé S, Dufresne CM, Loosereewanich P, Perrault G. Retention of asbestos fibres in lungs of workers with asbestosis, asbestosis and lung cancer, and mesothelioma in Asbestos township. Occup Environ Med 1996; 53: 801-807.

24. Sluis-Cremer GK, Bezuidenhout BN. Relation between asbestosis and bronchial cancer in amphibole miners. $\mathrm{Br}$
J Ind Med 1989; 46: 537-540.

25. Hughes JM, Weill H. Asbestosis as a precursor of asbestos-related lung cancer: results of a prospective mortality study. Br J Ind Med 1991; 48: 229-233.

26. Wilkinson P, Hansell DM, Janssen J, et al. Is lung cancer associated with asbestos exposure when there are no small opacities on the chest radiograph. Lancet 1995; 345: 1074 1078.

27. Henderson DW, de Klerk NH, Hammar SP, et al. Asbestos-related lung cancer: is it attributable to asbestosis, or to asbestos fiber burden? In: Corrin B, ed. Tumors of the Lung: Contemporary Issues. Edinburgh, Churchill Livingstone, 1997; pp. 83-118.

28. Churg AM, Warnock ML. Asbestos and other ferruginous bodies; their formation and clinical significance. Am J Pathol 1981; 102: 447-456.

29. Dumortier P, De Vuyst P, Strauss P, Yernault JC. Asbestos bodies in bronchoalveolar lavage fluids of brake lining and asbestos cement workers. Br J Ind Med 1990; 47: 91-98.

30. Moulin E, Yourassowsky N, Dumortier P, De Vuyst P, Yernault JC. Electron microscopic analysis of asbestos body cores from the Belgian urban population. Eur Respir J 1988; 1: 818-822.

31. Dodson RF, O'Sullivan M, Corn CJ, Garcia JGN, Stocks JM, Griffith DE. Analysis of ferruginous bodies in bronchoalveolar lavage from foundry workers. $\mathrm{Br} \mathrm{J}$ Ind $\mathrm{Med}$ 1993; 50: 1032-1038.

32. Roggli VL, Pratt PC. Numbers of asbestos bodies in iron-stained tissue sections in relation to asbestos body counts in lung tissue digests. Hum Pathol 1983; 14: 355361.

33. Craighead JE, Abraham JL, Churg A, et al. The pathology of asbestos-associated diseases of the lungs and pleural cavities: diagnostic criteria and proposed grading schema. Arch Pathol Lab Med 1982; 106: 544-596.

34. Monsó E, Texidó A, Lopez D, et al. Asbestos bodies in normal lung in Western Mediterranean populations with no occupational exposure to inorganic dust. Archiv Environ Health 1995; 50: 305-311.

35. Karjalainen A, Nurminen M, Vanhala E, Vainio H, Anttila S. Pulmonary asbestos bodies and asbestos fibers as indicators of exposure. Scand J Work Environ Health 1996; 22: 34-38.

36. Teschler H, Konietzko N, Schoenfeld B, Ramin C, Schraps T, Costabel U. Distribution of asbestos bodies in the human lung as determined by bronchoalveolar lavage. Am Rev Respir Dis 1993; 147: 1211-1215.

37. Teschler H, Hoheisel G, Fischer M, Müller KM, Konietzko $\mathrm{N}$, Costabel U. Asbestkörperchengehalt der bronchoalveolären Lavageflüssigkeit als Parameter einer erhöhten Asbestbelastung der Lunge. Dtsch Med Wochenschr 1993; 118: $1749-1754$.

38. De Vuyst P, Dumortier P, Moulin E, Yourassowsky N, Yernault JC. Diagnostic value of asbestos bodies in bronchoalveolar lavage fluid. Am Rev Respir Dis 1987; 136: 1219-1224.

39. Xaubet A, Rodriguez-Roisin R, Bombi JA, Marin A, Roca J, Agusti-Vidal A. Correlation of bronchoalveolar lavage and clinical and functional findings in asbestosis. Am Rev Respir Dis 1986; 133: 848-854.

40. Karjalainen A, Piipari R, Mäntylä T, Nykyri E, Tukiainen P, Anttila S. Asbestos bodies in BAL according to job trade. Eur Respir J 1996; 9: (Suppl. 23), 247s.

41. De Vuyst P, Dumortier P, Moulin E, et al. Asbestos bodies in bronchoalveolar lavage reflect lung asbestos body concentration. Eur Respir J 1988; 1: 362-367.

42. Teschler H, Friedrichs KH, Hoheisel B, et al. Asbestos 
fibers in bronchoalveolar lavage and lung tissue of former asbestos workers. Am J Respir Crit Care Med 1994; 149: 641-645.

43. Schwartz DA, Jeffery RG, Burmeister LF, et al. The clinical utulity and reliability of asbestos bodies in bronchoalveolar fluid. Am Rev Respir Dis 1991; 144: 684-688.

44. Pairon JC, Orlowski E, Iwatsubo Y, et al. Pleural mesothelioma and exposure to asbestos: evaluation from work histories and analysis of asbestos bodies in bronchoalveolar lavage fluid or lung tissue in 131 patients. Occup Environ Med 1994; 51: 244-249.

45. Modin BE, Greenberg SD, Buffler PA, Lockhart JA, Seitzman LH, Awe RJ. Asbestos bodies in a general hospital/clinical population. Acta Cytol 1982; 26: 667-677.

46. Teschler H, Thompson AB, Dollenkamp R, Konietzko N, Costabel U. Relevance of asbestos bodies in sputum. Eur Respir J 1996; 9: 680-686.

47. McDonald JC, Sebastien P, Case B, McDonald AD, Dufresne A. Ferruginous body counts in sputum as index of past exposure to mineral fibres. Ann Occup Hyg 1992; 36: 271-282.

48. Sulotto F, Capellaro E, Chiesa A, Villari S, Bontempi S,
Scansetti G. Relationship between asbestos bodies in sputum and the number of specimens. Scand J Work Environ Health 1997; 23: 48-53.

49. De Vuyst P, Missouni A, Van Muylem A, Rocmans P, Dumortier P. Systematic asbestos bodies counting in lung specimens resected for lung cancer. Eur Respir J 1997; 10: (Suppl. 25), 19s.

50. Johnston I, Britton J, Kinnear W, Logan R. Rising mortality from cryptogenic fibrosing alveolitis. Br Med J 1990; 301: 1015-1017.

51. Voisin C, Fisecki F, Voisin-Saltiel S, Ameille J, Brochard P, Pairon JC. Asbestos-related rounded atelectasis - radiologic and mineralogic data in 23 cases. Chest 1995; 107: 477-481.

52. De Vuyst P, Dumortier P, Jacobovitz D, Emri S, Cöplü L, Baris I. Environmental asbestosis complicated by lung cancer. Chest 1994; 105: 1593-1595.

53. Henderson D, Rantanen J, Barnhart S, et al. Asbestos, asbestosis and cancer. The Helsinki criteria for diagnosis and attribution. Scand J Work Environ Health 1997; 23: 306-311. 